Dr. Roe, however, gave no outline for internal medication, or what particular conditions were to be remedied by it. $\mathrm{He}$ reported thirty-six cures out of a total of forty-four cases by local treatment. From the nature of the disease it will be admitted that a permanent cure must come from treatment and relief of the excessively sensitive nasal mucous membrane and that cure will be hastened and the patient made comfortable during the treatment by internal medication. I believe that every case is curable by the combined treatment.

I report a few cases, with what seemed to be the most appropriate treatment for each case:

Case 1.-Miss I. M., aged 22, has had hay fever for the past three years. Her treatment consisted of chromic acid cauterization of the posterior ends of the inferior turbinated bodies and tricblor-acetic acid applications to the anterior extremities of the middle turbinated bodies, done during the season, with complete cure.

Case 2.-Mrs. N. H. has had a most severe case of hay fever extending over a period of twenty years. The nasal mucous membrane was greatly hypertrophied and very sensitive. I removed and cauterized the hypertrophies until I could find no more to treat. She still had some bay fever irritation but was greatly improved. Doses of 0.65 gram of salicylate of soda with each meal completed the cure for last season.

Corse 3.-Mr. H. W., aged 39 , with a rheumatic diathesis, a year ago developed hay fever, but has bad no recent treatment for abnormal nasal conditions. During the past season the Eymptoms of hay fever were kept under entire control by salicylate of soda and alkalin diuretics, but if they were discon tinued for a few days the symptoms would return.

Frilure to cure undoubtedly arises from placing our reliance in a single line of treatment, to the exclusion of other supplementrry measures, or inefficient intra-nasal treatment. There are hardly two cases alike and each should be studied for the best method of relief.

92 State Street.

\section{PHYSICAL DEFECTS IN PUPILS.}

Read at the Annual Meeting of the Associated Minnesota Sclool Boards, held at St. Pyul, Dec. 30, 1897

BY FRANK ALLPORT, M.D.

PROFESSOR OF OPITHALMOLOGY, CHICAGO POLICLINIC, ETC. CHICAGiO, IIL.*

I will take up that phase of the subject which deals with the problem of how best to preserve the eyesight of school children, a theme which is pregnant with importance. The prosecution of this subject opens up a wide field, involving not only those elements or conditions, which primarily and particularly bear upon ocular hygiene, such as print, lighting, etc., but also bear upon those circumstances obtaining during the school life of the child, which can either directly or indirectly affect the preservation or degeneration of his eyesight. Such consideration will lead us into a discussion of architecture, buildings, location, window space, lighting (natural and artificial), seats, desks, walls, black boards, maps, charts, paper, slates, printed matter, writing, etc.

The importance of this topic may be imagined, when we consider that James $\mathrm{H}$. Blodgett, in 1890, estimated that over fourteen million children were in attendance in the different schools and colleges of the United States. When we consider that the average of children possessing defective eyes in our schools is estimated to be from 25 to 30 per cent. it will be seen that at least three and one-half million children attending school in the United States possess defective eyes. It will thus be seen that the magnitude

* Formerly of Minneapolis, Minn. and importance of the problem, as to how best to subserve the ocular interests of this great number of school children, is enormous.

The consideration of defective eyes as a consequence of school life, was first publicly noticed by A. G. Beer, who, in 1890, published a treatise on "Healthy and Weak Eyes." He was followed, in his investigations, by Ware, Szokalski, Shurmayer, Jaeger, Reuta, Reck, Alexander, Gaertner, Cohn, Risley, Randall, and others. I, myself, have superintended the examination of over 10,000 pupils, in the Minneapolis public schools, the past year, by the method which I proposed in 1895. The Minneapolis tests have shown an average of 32 per cent. of children possessing defective eyesight. In all, between two and three hundred thousand children have been examined, according to different methods, in the schools of the world, and the percentages arrived at in Minneapolis are ubout the same as those obtained in other examinatjons, although in some of the German universities, where bad print, studious habits and hereditary influences are prominent, from 50 to 75 per cent. of ocularly defective students are not infrequently observed. The objective point obtained by these researches is the inevitable truth that myopia or short sightedness, or an elongated, softened eyeball, is the principal pathologic condition of the eye, induced in childre $n$ by study, and that the more imperfect the conditions under which the child studies, the more surely, steadily and rapidly will myopia develop.

The frequency of myopia in students has led some observers to believe it to be a natural evolution of tissue, incident and similar to the natural expansion and enlargement in other tissues of the body. These deductions are inaccurate and can not be substantiated. Such superficial observers evidently forget that the natural evolution to which they refer is practically a class evolution, and is found principally among students, or at least among those who attend schoul and use their eyes to a greater or less degree for the purpose of acquiring an education. Evolution of this kind does not exist to any great extent amongst those whose occupations are essentially separated from those of an educational nature. In other words, ocular examinatians among uneducated farmers, Indians and others, who practically never read or study, show the myopic eye to be conspiciously infrequent. People of such classes undergo evolution of tissue quite as much, and perhaps more so than the student, yet it is in the latter class that the elongated, softened, myopic eye plays such an important role. Myopia, therefore, while not confined to students, is especially frequent in them, and must inevitably be classed as a pathologic condition, and not a physiologic evolution, and is, unquestionably, principally caused by confinement and the more or less injudicious use of the visual organs. In other words, a myopic eye is a diseased eye, and should always be regarded and treated as such. The frequency of myopia has also led some observers to believe that a slightly myopic eye is the normal eye. This claim can not be substantiated, for a great number of observations have shown that the natural condition in infancy and early childhood is either emmetropia or hypermetropia.

Myopia is rarely seen before school life commences, some observers even claiming its non-existence in very early childhood. Its frequency steadily increases during school life, from class to class, and from room to room, and hypermetropia diminishes in proportion 
to the advance of myopia. Some authorities believe that myopia is not hereditary, only the tendency to myopia, and that this inherited tendency is augmented by certain abnormal and inherited shapes of the skull, socket, etc. While the infrequency of actual inherited myopia must be admitted, the statement that it is an absolutely uninherited condition is too sweeping, and the observation of whole families of myopic parents and children, which come under notice, from time to time, must convince an unbiased observer that myopia is a condition possible of transmission from one generation to another. If school life, with all its incident evils is capable of producing myopia, then it must be equally true that a mitigation or a removal of these evils, must be capable of decreasing the number of myopic children. That this is true, is amply proven by statistics gathered in this country and in Europe, where the proper correction of myopia by glasses, the erecting of more properly and ubundantly lighted schools, the improving of desks and seats, the changing of curriculums of study, etc., have unquestionably diminished the percentrge of myopes in a gifen community. In investigating this subject we are, therefore, not chasing an interesting scientific fact, but we are endeavoring to arrive at some truthful deductions which will enable us tu improve the ocular conditions of the coming generation.

The public schools of the United States are the crowning glory of this country. When we glance back at our own childhood days, and remember the hot, stuffy rooms, with their meager and poorly directed illumination, and the other unhealthy and unpleasant conditions and methods of obtaining a common school educution, and then pass through some of the beautiful school buildings of our cities with their cherrful and pleasunt surroundings, their teachers and general facilities, we can not but see that the public school system has improved and is improving sterdily, and that educators are eager to accept suggestions that will still further improve this system und reuder it as near perfect as possible. While I am well awure that the curriculums of study at present in vogue in our public schools are much less severe than those which formerly obtained, I believe them still to be excessive, and that they must inevitably, frequently tax, not only the ocular, but the general herith of students, especially those of weakly tendencies. I believe that a lengthening of the time required to secure a high school degree, by one year, would mitigate the severity of study all along the line, and enable scholars to emerge from their graduating exercises in better physical and mental condition, and would do the greatest good to the greatest number I believe, besides this, that a more elastic curriculum is necessary to favor children having poor eyes, and pour health. The strictness of the grades should be modified, at least, and permission given for individual studies to be taken in quantities somewhat adaptable to the health of given individuals. Credit should be given for such studies, as they are finished, and the child allowed to gruduate when all of the required studies have been completed. I am well aware, that this arrangement is not infrequently made in our pub. lic schools, but I think that such a course is not encouraged, and that children are made to feel a sense of mortification becuuse they are falling below their grades or classes. I think many of the children should belong to $m o$ grade or class, but be allowed to acquire their education, study by study, in a manner consistent with the proper development of the health. I do not mean to advocate the abandonment of grades and classes. This would be most unwise and undesirable, but I do feel that children with impaired ocular or general health should be cheerfully and creditably, not only allowed, but advised to take only such numbers of studies as will be consistent with a proper physical development. Such a course would lengthen the period of school life in many instances, but it would improve the average health of scholars, and this is of greater importance. Children should not be required to take so many studies that they have to work up two or three at home in the evening. If they study the major portion of the day, a crowing and developing child should not be required to give up that mental and physical relaxation incident to an evening spent pleasantly at home amid sports, games, music light literature, etc. I do not mean to say that children should do no studying at home of an evening. A little study is not only harmless, but beneficial, but some children are compelled to work up three or four studies at home, and this is excessive. Work of this kind resulting in close confinement, bad atmoephere. and perhaps poor illumination and utter disregard of hygienic study methods, results in a lack of that refreshing sleep necessary to the proper nervous, mental and physical development of the child. However much care is manifested in the schools coneerning the proper use of the eyes, it is difficult to regulate such work at home. Therefore the amount of required eyeservice at home should be limited. The teacher never knows how the scholar learns his lesson at home. $\mathrm{He}$ may study lying down by a poor light,or face a brilliantly lighted lamp or gas jet for hours, or indulge in other habits injurious to proper ocular health. Children will also use their eyes in devouring light and sensational literature, impressed upon the poorest paper, with the poorest type and the poorest ink: and while we may wish to stop this evil. we must be aware of our inefficiency in uccomplishing our desires. If this be true, and children's eyes will be abused in a manner that is thoroughly beyond our control, we must make some allowance for it and not impose too much ocular service at home, incident to the acquiring of an education. Ocular strain in schools can be much mitigated by frequent change of occupation, which may not be always a recess, but may be something in the nature of exercise of various kinds, such as calisthenics, gy m. nastics, marching, etc. Much improvement has been made along these lines of late yeurs, but there is further room for improvement. Such changes have become quite a feature in many German schools, where ocular degeneration has become recognized and steps for improvement inaugurated. Statistics from some schools have shown that since frequent breaks of various kinds in the school session have been made, the ocular condition of students have manifestly improved. The semi-annual term examination for the determination of class standing is often detrimental to the eyes and health of students. It is a semi-annual period of intense, concentrated and continuous study which often leaves in its wake impaired oyes and health. Can not some means be devised whereby these periods of over study and anxiety may be abated, and the standing of students secured in other ways, such as class records, quizzes, reviews, etc?

The architecture and location of school buildings is of great importance. Suitable and healthy loca. 
tions should be obtained as far as possible. In cities, the nature of the soil is not always possible to be taken into consideration, nor is it so important, as city buildings are usually thoroughly well drained and plumbed. In the country, however, a well drained location should be chosen, without a clay sub-soil, and remote from malarial and other injurious environments. In cities, narrow streets with high buildings should be avoided, as they shut out the light and proper ventilation. School buildings should be away from factories. markets, etc, to avoid their distracting noises, exhalations dust, etc. Ample grounds should be secured, upon all sides of the building, not only for maintaining proper air, light, etc., but in order that children may have plenty of room for games, etc., which are so conducive to the proper physical development of the child. Large, well lighted and dry cellars should be had for recreation on stormy days, and, where it is impossible to obtain a large tract of ground for the school building, it has been suggested that a flat roof be built with high surrounding walls and a roof garden be laid out in which children may play. The question of sufficient light in school buildings is of vital importance. To obtain this, other buildings should be at a distance equal to twice their height from the school building. The illumination of a school room should be of a quantity and quality that will amply light every portion of the room on a dark day. To secure this, the window surface should not be less than one-fifth or one-sixth of the floor, and the direction from which the illumination comes is a matter that is not particularly essential, although a north light is the steadiest and most constant; but many observers and teachers dislike it on account of the lack of sunlight, which they claim to be detrimental to the health and spirits. Scholars compelled to study by poor illumination will be found to carry the printed page close to the eye, in order to increase the quantity of retinal illumination, or to take advantage of the law that the illumination diminishes according to the square of the distance. This forces the accommodation and convergence of the optical axes, and causes undue congestion of the eyeball and surrounding tissues, which increases intraocular pressure and softens the coats of the eye, thus permitting an elongation of the optical axis, and the production of myopia. Windows should be at the side of the room, preferably the left side, and at the back. The lower portion of the window should be about three feet from the floor and extend to the ceiling, in order to obtain as much window space as possible. The margins of the window ledges should be beveled, both inside and out, to avoid shadows, and should not be placed on both sides of the room, as it would result in a confusing and injurious cross-light. There should be as little wall space on the sides where the windows are placed as possible, and the windows should be hinged at the top, in order to obtain proper ventilation without direct draughts. Blackboards should not be placed between windows, as it taxes the eye exceedingly to endeavor to decipher marks made upon a blackboard thus situated. The ceilings of a school room should be high, in order to secure good light and ventilation. Artificial illumination should be of a good quality and sufficient in quantity. A profusion of incandescent lights with glazed globes, grouped at frequent intervals, is the best illumination that can be secured, as it is white in character, intense in quality, and does not heat or vitiate the atmosphere. In order to carry out the idea of a light school room, the walls should be painted in delicate shades of yellow, green, blue or light gray. The blackboards can be covered when not in use by light colored shades, of a similar color to that of the walls. The woodwork, desks, etc., should be all of light colored wood, in order to preserve as much illumination as possible. Window shades should be light colored, and should roll from both the top and bottom, with the possibility of their being long enough to roll up or down the full extent of the window surface.

The seats and desks is an item of great importance, and was first publicly mentioned by Henry Barnard in 1860 He pointed out the necessity of placing the seats close to the desks in order to avoid leaning forward. Seats and desks should be arranged in such a manner that the soles of the feet will rest securely upon the floor, and so that the erect posture is the most natural and the easiest for the scholar to assume. In order to obtain this the seats should be as wide as the thigh is long, measured from the inner bend of the knee to the back. It should be level and slightly concaved to prevent slipping forward. The front edge of the seat should be placed from one to two and a half inches underneath the inner edge of the desk. The top of the desk should be inclined toward the pupil at an angle of about 10 degrees, and must be low enough to allow the forearm of the pupil to rest lightly upon it without raising the shoulder when in the act of writing, but sufficiently high to avoid the necessity for stooping in order to reach it. The lower part of the back and pelvis should be supported by a rest easily felt while sitting upright. It seems almost unnecessary to state that desks should be of different sizes to suit the pupils, and yet I have frequently looked into schoolrooms where but little attention was paid to this point. Some of the manufacturers construct desks in such a manner that by the adjustment of screws, etc., every desk in the room can be made of a proper size to any child who will be likely to be in that particular schoolroom. By using desks of this kind, the fitting of scholars to their desks will be an important procedure at the commencement of each school year. Of course, proper desks or seats will not solve the problem, some children have weak backs or are otherwise bodily affected and seem truly unable to sit in a schoolroom without half reclining upon a desk, and it is questionable whether children of this kind should be required to attend school sessions steadily. Other children are lazy and slouchy in their habits, and this will call for frequent admonishment on the part of their teacher.

Blackboards should be kept clean and have unglazed surfaces, and the figures, lines, etc., that are marked upon them should be of a size and character that can be easily seen without straining the eyes of the pupils. Some authorities have recommended the use of white boards with black chalk instead of blackboards with white chalk, as black figures on a white surface can unquestionably be seen easier and farther than white figures on a black surface. I think a majority of practical educators, however, believe that the white boards with black chalk are extremely objectionable, on account of the constant and distasteful soiling of the hands. If the blackboards are kept clean, the white crayon marks will be found to be sufficiently legible for all practical purposes.

Slates are justly becoming unpopular in schools, whether they be black or white, on account of the 
foul and unhealthy condition in which they become. If slates are used, however, the white slates are to be preferred, as the black marks upon the white surface are much less trying to the eye than the faint gray marks of the pencil upon the old-fashioned slates. The best material with which to perform this kind of work is whited unglazed paper and black ink, with a stub pen capable of making heavy strokes. Maps and charts are important articles of school furniture and easy to teach with, if the marks upon them are large and legible. The groundwork upon which such maps are printed should be of a white or yellow color, as characters printed upon dark shades, such as red or blue are not so easily distinguished. The study of geography as taught by hand atlases, with varied colors, lines, figures, printing, etc., is very trying, and is probably more injurious to the eye than any other study. Great care should, therefore, be taken in the printing of geographic text-books and maps, and such books should be chosen by school authorities as will be least in jurious to the visual organs of the child.

The manufacture of text-books for schools is a subject of great importance. Books should be of a size that can be easily handled, and the paper used in the construction should be of good quality, non-translucent, reasonably thick and of white or cream color The printing should be first-class in every particular. The letters should be black, clear and of sufficient size for easy reading. The lines should have good distances between them. Long lines should be avoided, as extra accommodation is required to follow them, and if a page must be wide it is better to divide its contents into columns.

A great deal of discussion has lately arisen as to whether the slanting handwriting heretofore taught in our schools should be continued, or whether scholars should be instructed as to the methods of acquiring an erect handwriting. Fahrner, in 1897, said, "we allow our children to grow crooked in order that their handwriting may be nicely slanted." There can be no question but that vertical handwriting is less injurious to the eye than the slanted variety. In writing after the vertical method, the paper is directly in front of the scholar, and therefore the page is seen equally well with both eyes, which will accordingly work together. Besides this, the strokes are stronger and less hair lines will be seen than in the slanted variety. Besides, the vertical method of writing favors upright sitting, which is in itself a sufficient reason for its adoption.

The tendency to leun over while sitting at the desk is very strong with some scholars, even though the school authorities have provided them with proper desks and seats. To obviate this tendency, many forms of head rests or face rests have been suggested, and of them all Kallman's face rest is probably the best. These rests are fastened to the desk and assume a vertical position with a loop at the extremity through which the face emerges. When these rests are fastened into the desks it becomes impossible for the child to lean over when reading, and many German schools have adopted Kallman's face rests with the utmost satisfaction.

The method which I proposed in February, 1895, for the detection of most ocular diseases in children, together with measures for their relief, is doubtless familiar to all. I have from time to time modified the original plan until I believe it to be now as nearly as perfect as such a plan can be in our American public schools.

The statistical papers and warning cards now in use in the Minneapolis schools are now used quite generally throughout the United States, and are giving satisfaction wherever tried. The results have been distinctly beneficial to the coming generation, and in Minneapolis the plan is in great favor with teachers, scholars, parents and the public at large, and has been productive of benefit to thousands of cases, especially since people are learning that the tests are for the development of most all ocular diseases and not merely for the fitting of glasses, and since they have also learned that an eye doctor and not an optician is the proper person to consult if a warning card is deemed a necessity.

Those aural diseases which will be most frequently observed by teachers are running or matterating ears and deafness. The former are usually produced from blood diseases, inherited or acquired, from catching cold or from catarrhal affections of the throat and nose. They can usually be detected by the teacher if the child complains of earache if care is taken to look into each ear, as far as possible, by a good light for the detection of matter or pus, or if either ear emits a foul odor. If any of these conditions obtain, the child should be advised to consult an aurist.

I would recommend that the following questions he added to the statistical blanks now in use in the Minneapolis schools:

1. Does the pupil frequently complain of earache in ither ear?

2. Does matter (or pus) flow from either ear?

3. Does a foul odor proceed from either ear?

If an affirmative answer obtains from any of these questions the child should be sent to an ear doctor, as often questions not of diseased ears but life and death itself are at issue. The examination for odor will be most distasteful to some teachers, and under such circumstances it may be omitted.

A deaf child is an apparently stupid child and is deprived to a greater or less extent of an important sense which was intended as one of the means of obtaining a knowledge of the world. $\mathrm{He}$ is therefore unequally equipped for the battle of life and obtains an education disadvantageously, and is frequently called stupid, listless and unambitious, when in reality he is merely deaf. The time to relieve such conditions is in early life while physical tissues are pliable, and not in later years when relief is improbable and cure well nigh impossible.

Deatness may be due to the presence of a matterating (or purulent) ear with its destructive tissue changes, which causes will be developed under the set of questions just enumerated, or it may be due to catarrhal conditions or changes of the throat, nose or Eustachian tube. One of the most frequent causes of deafness in children is what is known as adenoid vegetations in the vault of the pharynx, or enlarged bunches of tissue growing from the upper portion of the throat and interfering with the proper inhalation and exhalation of air through the nostrils, and the, proper aeration of the middle ear through the Eustachian tubes. The same unfortunate conditions exist frequently in children possessing abnormally large tonsils. Children of this kind are apt to become deaf and develop into what are known as "mouth breathers," because they habitually breathe through their mouth instead of their nostrils, giving them a peculiarly stupid and vacant appearance. The improper aeration of the air passages predisposes to lung 
diseases, and the perpetual expansion of the mouth and the lack of nasal breathing produce a lateral contraction of the nose and vault of the mouth which, together with the contracted upper lip, gives to the countenance a characteristic appearance, which once seen is not easily forgotten. Almost inevitably a child with such a physiognomy is more or less deaf and has throat or nose obstructions, or both. Other catarrhal conditions may cause deafness and frequently do, but such events occur more frequently in adults. The deafness of children is usually dependent upon organized nose or throat obstructions. These conditions can be easily detected by an unprofessional observer by the appearance of the child and the asking of a few simple questions.

Before suggesting these questions let me say that while there are many tests for hearing, only two seem feasible for use in school examination, viz, the spoken voice and the tick of a good sized watch. To use the former the child's back should be turned to the teacher, and an assistant should plug up first one ear and then the other with a cloth over the finger. The teacher should then step away about twenty feet, and ask the child in a low but distinct voice, a direot question, requiring a direct answer. If, after one or two tests the child fails to hear the spoken words in either ear, he should be sent to an ear doctor. He should be further tested in the same way in both ears, by the tick of a good sized watch, which should be placed six or eight feet away, and gradually moved toward the child, on the side upon which he is being tested. The watch should be heard at least three feet away, and if it is not heard by both ears at that distance, the child should be sent to an ear doctor.

Having now shown you how hearing may be simply tested, let me suggest some pertinent questions, to be added to the statistical blanks previously recommended, which will develop the existence of the abnormal conditions, which I have endeavored to briefly describe:

1. Does the pupil fail to hear a low and distinct voice, at twenty feet, with each ear?

2. Does the pupil fail to hear the tick of a good sized watch at three feet, with each ear?

3 . Can matter be seen flowing from either ear, or does a foul odor proceed from either ear?

4. Does the child fail to breathe freely from either nostril, when the other nostril is closed with the finger?

5 . Is the child an habitual "mouth breather"?

If an affirmative answer is given to any of these questions the child should be sent to an ear doctor.

The results of intelligent treatment upon such diseases in children are exceedingly satisfactory, and if the young sufferers can be placed under proper care sufficiently early, an immense amount of good may be accomplished to the coming generation.

92 State Sreet.

\section{THE BEST METHODS OF SURGICAL} STERILIZATION

Presented in the Fourth Annual Meeting of the American Academy of Railway Surgeons at Chicago, Ill., Oct. 6-8, 1897. BY EDUARD BOECKMANN, M.D.

CONSULTING SURGEON CHICAGOGREAT WESTERN RAILWAY. ST. PAUL, MINN.

It is indeed very fortunate that the surgical bacteria are, comparatively speaking, so little resistant that surgical sterilization can be reduced to such a degree of simplicity that it may be carried out on short notice, not only in hospitals, but also under the open sky, not only in private practice, but also in offices, by reasonable means and in reasonable time. While surgical sterilization is open to improvement and does steadily improve, it is a source of some regret that the best methods of accomplishing surgical sterilization are still somewhat in dispute.

If I am justified in considering the various manuals on this topic, as standards for the teachings and practice of surgical sterilization in the respective countries, we have three principal schools before us: 1, the Eng. lish school, which practically teaches the destruction of pyogenic, consequently non-spore-bearing bacteria only. (W. Watson Cheyne: "The Treatment of Wounds, Ulcers and Abscesses," Philadelphia, 1895); 2 , the German school, which advocates the extermination of all surgical bacteria, spore-bearing or not, pyogenic or not. (C. Schimmelbusch: "Anleitung zur aseptischen Wundbehandlung," Berlin, 1893); 3 , the French school, which in reality aims at the destruction of all kinds of bacteria, pathogenic or not, consequently not only at surgical but also at bacteriologic sterility. (Felix Terrier and M. Peraire: "Petit Manuel d'Antisepsie et d'Asepsie chirurgicales," Paris, 1893.)

The practical result of these three different views is, that the Englishman is perfectly content with chemical sterilization, while the German considers thermic sterilization the best method, as does the Frenchman.

If the Englishman is right he has the advantage of the simplest method of sterilization, as almost every. thing is prepared with the aid of a cold solution of carbolic acid; if the German is right, and he has at least the sympathy of the majority of surgeons, steril. izers for boiling water and for ordinary steam, which the Englishman bas no use for, are indispensable; and if the Frenchman is right, surgical sterilization will never become popular outside of hospitals, as his sterilizers are both expensive and cumbersome, as they are constructed for high pressure.

Surgical sterilization means, naturally, destruction of surgical bacteria, and is a part only of asepsis, which means absence of all septic material, consequently not only of bacteria, but also of impurities of a chemotactic nature. In our surgical work we aim consequently, not only at sterility but at cleanliness (atoxicity) as well. This fact is admitted by all schools, and mechanical sterilization is therefore recognized as a preliminary measure of the highest importance. Chemic and thermic sterilization can not satisfactorily cleanse all our various articles; on the other hand, mechanical sterilization is not able to sterilize them perfectly, although this last method removes the majority of the bacteria at the same time that it makes the articles atoxic.

While it is of some importance to remove chemic impurities of all kinds, and all schools, therefore, in. dulge in washing, scrubbing, scraping and shaving, and while mechanical sterilization at the same time means at least three-fourths sterility, we must insist upon complete destruction of our real enemies. The question now is, is it enough to destroy the less resistant pyogenic bacteria (English), or is it necessary to remove and kill all known surgical bacteria and their spores (German), or finally, should we endeavor to obtain a real bacteriologic sterility (French)?

It must be admitted that failures in our surgical work, because of imperfect sterilization, are invariably 